\title{
Prognostic value of differentiation status in gastric cancer
}

\author{
Fan Feng ${ }^{1 \dagger}$, Jinqiang Liu ${ }^{1,2+}$, Fei Wang ${ }^{1,3+}$, Gaozan Zheng ${ }^{1}$, Qiao Wang ${ }^{1,4}$, Shushang Liu', Guanghui Xu1', Man Guo , \\ Xiao Lian ${ }^{1}$ and Hongwei Zhang ${ }^{1 *}$ (i)
}

\begin{abstract}
Background: Up to date, investigation of the prognostic value of differentiation status mainly focused on signet ring cell and mucinous gastric cancer. Thus, the present study aims to investigate the clinicopathological features and prognosis of gastric cancer patients with well, moderately and poorly differentiation status.

Methods: From September 2008 to March 2015, a total of 3090 gastric cancer patients treated with radical D2 gastrectomy were enrolled in the present study. Clinicopathological characteristics and prognosis of gastric cancer patients with well, moderately and poorly differentiation status were analyzed.

Results: There were 2422 male (78.4\%) and 668 female (21.6\%). The median age was 58 (20-90) years. There were 370 (12.0\%) well differentiated tumors, 836 (27.0\%) moderately differentiated tumors and 1884 (61.0\%) poorly differentiated tumors. Well and moderately differentiation status were associated with older age, male gender, smaller tumor, shallower invasion, less lymph node involvement and earlier tumor stage (all $p<0.001$ ). Inversely, poorly differentiation status was associated with younger age, female gender, larger tumor, deeper invasion, more lymph node involvement and later tumor stage (all $p<0.001$ ). With respect to prognosis, well differentiation status was associated with favorable overall survival and poorly differentiation status was associated with unfavorable overall survival $(p<0.001)$. However, after matching with age, tumor size, $\mathrm{T}$ and $\mathrm{N}$ stage, there was no significant difference among the overall survival of the three groups $(p=0.415)$.

Conclusions: Well, moderately and poorly differentiation status was significantly associated with clinicopathological features of gastric cancer patients. However, it was not associated with the prognosis of gastric cancer patients.
\end{abstract}

Keywords: Gastric cancer, Differentiation status, Clinicopathological characteristics, Prognosis

\section{Background}

Despite the decreasing overall worldwide incidence of gastric cancer in the recent decades, it is still the fifth most common malignant tumors and the third leading cause of cancer-associated death in the world [1]. Furthermore, it is the second commonest cancer in China [2]. Surgical resection with extended lymph node clearance remains the only curative option for non-metastatic gastric cancer [3-5]. Although with the significant improvement in surgical techniques

\footnotetext{
* Correspondence: zhanghwfmmu@126.com

${ }^{\dagger}$ Fan Feng, Jinqiang Liu and Fei Wang contributed equally to this work.

'Division of Digestive Surgery, Xijing Hospital of Digestive Diseases, Fourth Military Medical University, 127 West Changle Road, Xi'an 710032, Shaanxi, China

Full list of author information is available at the end of the article
}

and adjuvant therapy, the prognosis of gastric cancer is still not promising [6]. Thus, the prognostic risk factors for gastric cancer have been widely investigated, and age, tumor location, tumor size, tumor depth and lymph node metastasis, etc. $[4,7,8]$ have already been demonstrated to be associated with the prognosis of gastric cancer patients previously.

Up to date, the investigation of the prognostic value of differentiation status mainly focused on signet ring cell (SRC) and mucinous carcinoma, which were classified as undifferentiated type according to the Japanese classification of gastric carcinoma [9]. However, the prognostic significance of SRC and mucinous gastric carcinoma are still controversial [10-14]. Previously, we also investigated the clinicopathological

(c) The Author(s). 2018 Open Access This article is distributed under the terms of the Creative Commons Attribution 4.0 International License (http://creativecommons.org/licenses/by/4.0/), which permits unrestricted use, distribution, and reproduction in any medium, provided you give appropriate credit to the original author(s) and the source, provide a link to the Creative Commons license, and indicate if changes were made. The Creative Commons Public Domain Dedication waiver (http://creativecommons.org/publicdomain/zero/1.0/) applies to the data made available in this article, unless otherwise stated. 
features and prognostic value of mucinous gastric cancer, and found that the prognosis of mucinous tumor was comparable with non-mucinous tumor [15]. However, the clinicopathological characteristics and prognosis of patients with well, moderately and poorly differentiated gastric cancer have not been reported yet. Thus, the present study aims to investigate the clinicopathological features and prognosis of gastric cancer patients with well, moderately and poorly differentiation status.

\section{Methods}

This study was performed in the Division of Digestive Surgery, Xijing Hospital of Digestive Diseases. From September 2008 to March 2015, a total of 3090 consecutive gastric cancer patients were enrolled in the present study. All patients were treated with radical D2 gastrectomy [16] and regular follow up. This study was approved by the Ethics Committee of Xijing Hospital, and written informed consent was obtained from all patients before surgery.

Clinicopathological data including age, gender, tumor location, tumor size, differentiation status, tumor depth, lymph node metastasis and tumor stage were collected. Patients were divided into three groups according to differentiation status: well, moderately and poorly differentiation. The patients were followed up till November 2016.

Data were processed using SPSS 22.0 for Windows (SPSS Inc., Chicago, IL, USA). Discrete variables were analyzed using Chi-square test or Fisher's exact test. We respectively matched the 1884 patients in

Table 1 Clinicopathological characteristics of gastric cancer patients

\begin{tabular}{|c|c|c|c|c|}
\hline Characteristics & Well, $n(\%)$ & Moderately, n (\%) & Poorly, n (\%) & $P$ value \\
\hline Age & & & & $<0.001$ \\
\hline$\leq 60$ & 197(10.8) & $406(22.2)$ & $1226(67.0)$ & \\
\hline$>60$ & 173(13.7) & $430(34.1)$ & $658(52.2)$ & \\
\hline Gender & & & & $<0.001$ \\
\hline Male & $308(12.7)$ & $716(29.6)$ & 1398(57.7) & \\
\hline Female & $62(9.3)$ & $120(18.0)$ & $486(72.7)$ & \\
\hline Tumor location & & & & $<0.001$ \\
\hline Upper third & 146(14.9) & $351(35.7)$ & $485(49.4)$ & \\
\hline Middle third & $47(9.3)$ & 108(21.4) & $350(69.3)$ & \\
\hline Lower third & 163(12.0) & $329(24.2)$ & $867(63.8)$ & \\
\hline Cross or entire & $14(5.7)$ & $48(19.7)$ & 182(74.6) & \\
\hline Tumor size & & & & $<0.001$ \\
\hline$\leq 5$ & $332(15.3)$ & $613(28.2)$ & $1228(56.5)$ & \\
\hline$>5$ & $38(4.2)$ & $223(24.3)$ & $656(71.5)$ & \\
\hline Tumor depth & & & & $<0.001$ \\
\hline $\mathrm{T} 1$ & 193(32.9) & $165(28.2)$ & 228(38.9) & \\
\hline $\mathrm{T} 2$ & $49(10.1)$ & 153(31.5) & $284(58.4)$ & \\
\hline T3 & $96(8.6)$ & $351(31.4)$ & $670(60.0)$ & \\
\hline T4 & $32(3.6)$ & $167(18.5)$ & 702(77.9) & \\
\hline Lymph node metastasis & & & & $<0.001$ \\
\hline No & $274(24.2)$ & $360(31.8)$ & 498(44.0) & \\
\hline N1 & $52(8.8)$ & 200(33.8) & $340(57.4)$ & \\
\hline N2 & $27(5.1)$ & $142(26.8)$ & $361(68.1)$ & \\
\hline N3 & $17(2.0)$ & 134(16.0) & $685(82.0)$ & \\
\hline Tumor stage & & & & $<0.001$ \\
\hline I & $225(28.9)$ & $241(31.0)$ & $312(40.1)$ & \\
\hline$\|$ & $93(10.1)$ & $316(34.3)$ & $511(55.6)$ & \\
\hline III & $52(3.7)$ & $279(20.1)$ & $1061(76.2)$ & \\
\hline
\end{tabular}


poorly differentiation group and 836 patients in moderately differentiation group to the 370 patients who in well differentiation group with a 1:1 matched ratio. The gmatch macro of SAS 9.2 (SAS institute, Cary, NC, USA) written by Erik Bergstralh \& Jon Kosanke (http://bioinformaticstools.mayo.edu/research/ gmatch/) was used to execute this pair matching process. The principle of this macro is computerized matching of cases to controls using the greedy matching algorithm with a fixed number of controls per case. Controls may be matched to cases using one or more factors (X's). In this study, we set patients in well differentiation group as cases, and patients in moderately or poorly group as controls. The matching condition/factors we set among the four groups based on the following three parameters: age $( \pm 10$ years), tumor size $( \pm 1 \mathrm{~cm}), T$ stage and $\mathrm{N}$ stage. The study endpoint was OS (Overall survival), the time to event was computed from the date of surgery to the date when the death (any cause) was recorded. Overall survival curves were estimated by the Kaplan-Meier method and comparison between survival curves was performed using the log-rank test. The $p$ value was considered to be statistically significant at $5 \%$ level.

\section{Results}

There were 2422 male (78.4\%) and 668 female (21.6\%). The median age was $58(20-90)$ years. There were $370(12.0 \%)$ well differentiated tumors, 836
(27.0\%) moderately differentiated tumors and 1884 (61.0\%) poorly differentiated tumors. The associations between differentiation status and clinicopathological features were summarized in Table 1 . The proportion of well and moderately differentiation status were higher in patients older than 60 years old, in male patients and in patients with tumors smaller than $5 \mathrm{~cm}$. It also gradually decreased along with the $\mathrm{T}$ stage, $\mathrm{N}$ stage and TNM stage. Inversely, the proportion of poorly differentiation status was higher in patients younger than 60 years old, in female patients and in patients with tumors larger than $5 \mathrm{~cm}$. It also gradually increased along with $\mathrm{T}$ stage, $\mathrm{N}$ stage and TNM stage.

The overall survival of patients with different differentiation status were analyzed and shown in Fig. 1. The results showed that the overall survival of patients was gradually decreased along with the differentiation status. However, the difference only existed in patients with stage III tumors in the subgroup analysis.

Due to the unbalanced baseline distribution, patients in the three groups were matched based on age, tumor size, $\mathrm{T}$ stage and $\mathrm{N}$ stage. The clinicopathological features were compared and shown in Table 2. The results showed that the distribution of age, tumor size, $\mathrm{T}$ stage, $\mathrm{N}$ stage and TNM stage were all comparable among the three groups (all $p>$ $0.05)$. Further, the overall survival of patients was analyzed and shown in Fig. 2. The results showed
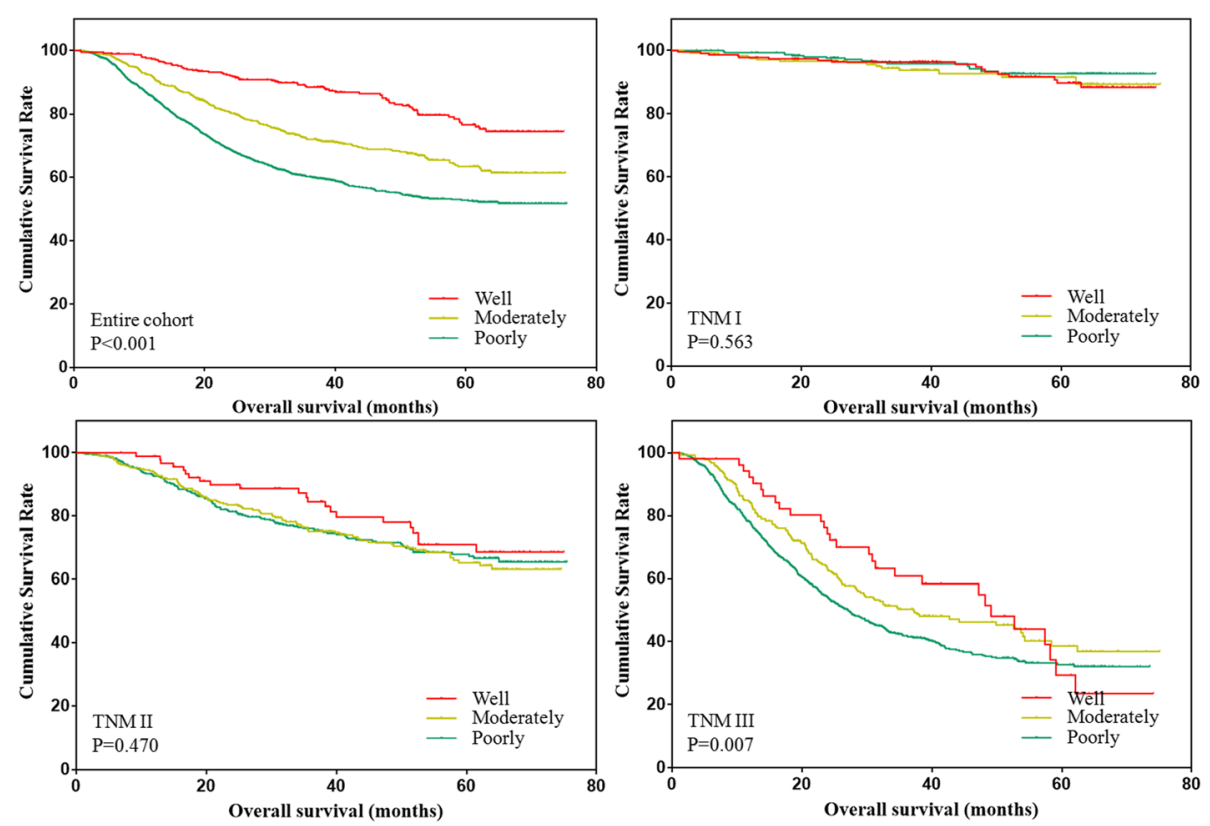

Fig. 1 Overall survival of patients with different differentiation status 
Table 2 Clinicopathological characteristics of gastric cancer patients after match

\begin{tabular}{|c|c|c|c|c|}
\hline Characteristics & Well & Moderately & Poorly & $P$ value \\
\hline Age & & & & 0.761 \\
\hline$\leq 60$ & 176 & 180 & 185 & \\
\hline$>60$ & 131 & 127 & 122 & \\
\hline Gender & & & & 0.001 \\
\hline Male & 254 & 264 & 230 & \\
\hline Female & 53 & 43 & 77 & \\
\hline Tumor location & & & & $<0.001$ \\
\hline Upper third & 123 & 111 & 60 & \\
\hline Middle third & 36 & 45 & 60 & \\
\hline Lower third & 135 & 141 & 170 & \\
\hline Cross or entire & 13 & 10 & 17 & \\
\hline Tumor size & & & & 0.654 \\
\hline$\leq 5$ & 271 & 270 & 264 & \\
\hline$>5$ & 36 & 37 & 43 & \\
\hline Tumor depth & & & & 1.000 \\
\hline $\mathrm{T} 1$ & 132 & 132 & 132 & \\
\hline $\mathrm{T} 2$ & 48 & 48 & 48 & \\
\hline $\mathrm{T} 3$ & 96 & 96 & 96 & \\
\hline T4 & 31 & 31 & 31 & \\
\hline Lymph node metastasis & & & & 1.000 \\
\hline No & 213 & 213 & 213 & \\
\hline N1 & 50 & 50 & 50 & \\
\hline N2 & 27 & 27 & 27 & \\
\hline N3 & 17 & 17 & 17 & \\
\hline Tumor stage & & & & 0.999 \\
\hline I & 164 & 164 & 164 & \\
\hline$\|$ & 92 & 94 & 94 & \\
\hline III & 51 & 49 & 49 & \\
\hline
\end{tabular}

that there was no significant difference among the prognosis of three groups.

\section{Discussion}

Up to date, the investigation of the prognostic value of differentiation status mainly focused on SRC and mucinous gastric carcinoma. Although SRC and mucinous carcinoma have long been regarded as adverse prognostic risk factors of gastric cancer, the findings of previous reports were inconsistent. This may attribute to the different sample size, race and inclusion criteria etc. in these studies. Further, in the previous reports, gastric cancer patients with SRC or mucinous differentiation status were always compared with non-SRC or non-mucinous differentiation status. The features of patients with well, moderately and poorly differentiation status have not been investigated in detail. Thus, our present study aims to elucidate the clinicopathological characteristics and prognosis of gastric cancer patients with well, moderately and poorly differentiation status. We found that differentiation status was significantly associated with age, gender, tumor location, tumor size, tumor depth, lymph node metastasis and tumor stage, but not the prognosis of gastric cancer.

In many previous reports, SRC histology appears to occur frequently in female and young patients [13, 17-19], whereas mucinous histology was not associated with gender and age of patients [10, 15, 20]. In our present study, the distribution of differentiation status was significantly associated with gender and age of patients. In detail, well and moderately differentiation status occurred more frequently in male and old patients, whereas poorly differentiation status mainly occurred in female and young patients. This was similar to the findings in patients with SRC histology in the previous reports.

Both SRC and mucinous histology were reported to be significantly associated with larger tumor size, deeper tumor invasion, more lymph node metastasis and later tumor stage in the previous reports $[10,13,15$, 20]. In our present study, we found the same tendency. Moreover, we found that the proportion of well and moderately differentiation status gradually decreased along with the $\mathrm{T}, \mathrm{N}$ and TNM stage. Inversely, the proportion of poorly differentiation status gradually increased along with T, N and TNM stage. This indicated that well-moderately-poorly differentiation status transition or dedifferentiation-redifferentiation may occur in single tumor during progression of disease [21-26]. However, the potential mechanism needs further investigation.

Up to date, reports about the prognostic value of differentiation status mainly focused on SRC and mucinous carcinoma, and results were inconsistent. Piessen et al. reported that SRC histology was an independent risk factor for the poor prognosis of gastric cancer [14]. Postlewait et al. reported that SRC histology was not independently associated with reduced recurrence free survival and overall survival [13]. However, Wang et al. reported that SRC histology had a relatively favorable prognosis of early gastric cancer [12]. In addition, findings about the prognostic value of mucinous carcinoma were also controversial [10, 11, 20, 27]. The association between well, moderately and poorly differentiation status and prognosis of gastric cancer patients have never been investigated before. In our present study, differentiation status was significantly associated with the overall survival of gastric cancer patients through Kaplan-Meier analysis. However, considering the 

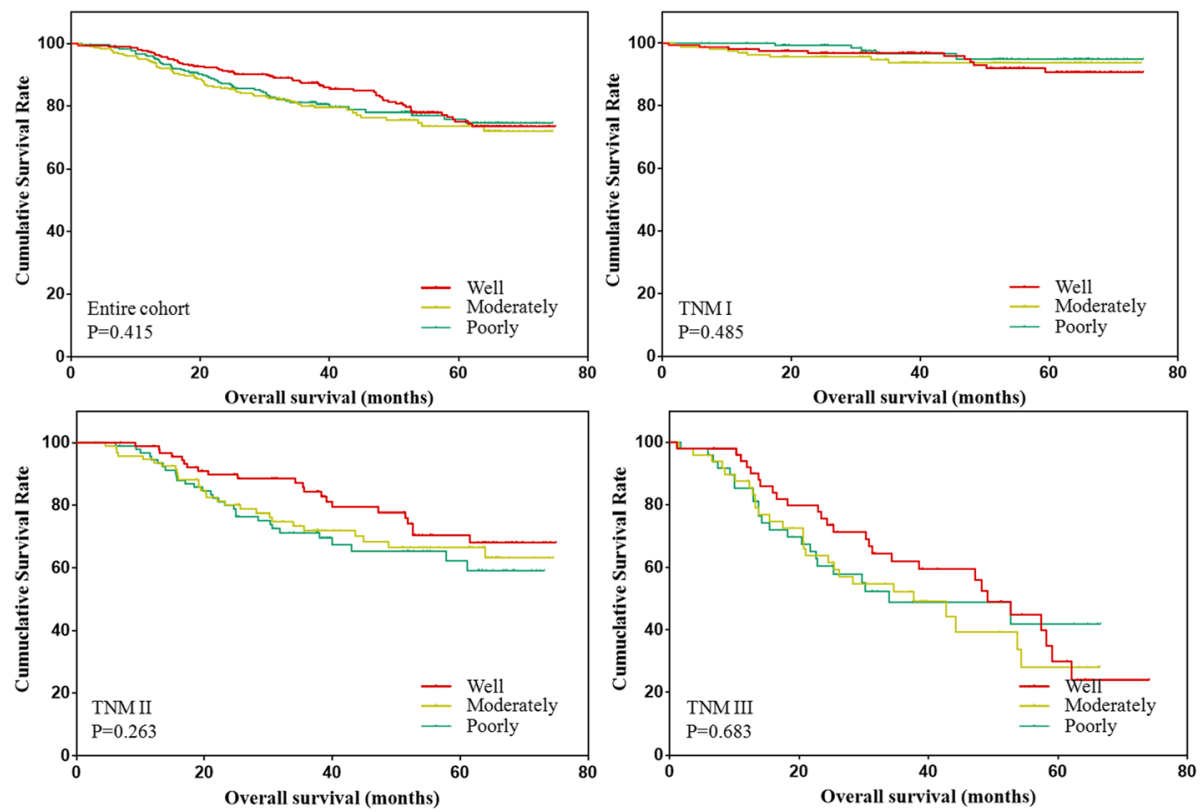

Fig. 2 Overall survival of patients with different differentiation status after match

significant association between pathological features and differentiation status, patients in the three groups were matched based on age, tumor size, $\mathrm{T}$ stage and $\mathrm{N}$ stage. As a result, the overall survival was comparable between well, moderately and poorly differentiation status after match. This indicated that well, moderately and poorly differentiation status was not associated with the prognosis of gastric cancer patients.

There were several limitations in our present study. First, it was a retrospective and single center analysis with relatively limited sample size. Multi-center studies are needed to verify the findings in our present study. Second, disease free survival and disease specific survival were not analyzed. Third, only age, tumor size, $\mathrm{T}$ stage and $\mathrm{N}$ stage were matched, which may result in bias during analysis. Fourth, SRC and mucinous histology were not included in the present analysis.

\section{Conclusions}

Well, moderately and poorly differentiation status was significantly associated with clinicopathological features of gastric cancer patients. However, it was not associated with the prognosis of gastric cancer patients.

\section{Abbreviations}

SRC: signet ring cell

\section{Funding}

This study was supported in part by grants from the National Natural Scientific Foundation of China [NO. 31100643, 31570907, 81300301, 81572306, 81502403].

\section{Availability of data and materials}

The datasets used and/or analysed during the present study are available from the corresponding author on reasonable request.

\section{Authors' contributions}

FF, JQL and FW conceived the study and drafted the manuscript. GZZ, QW SSL, GHX collected the data. MG, XL performed statistical analysis. HWZ designed and supervised the study. All authors read and approved the final manuscript.

Ethics approval and consent to participate

This study was approved by the Ethics Committee of Xijing Hospital, and written informed consent was obtained from the patients in our center.

\section{Consent for publication}

Not applicable.

\section{Competing interests}

All of the authors declare that there are no financial or other relations that could lead to a conflict of interest.

\section{Publisher's Note}

Springer Nature remains neutral with regard to jurisdictional claims in published maps and institutional affiliations.

\section{Author details}

${ }^{1}$ Division of Digestive Surgery, Xijing Hospital of Digestive Diseases, Fourth Military Medical University, 127 West Changle Road, Xi'an 710032, Shaanxi, China. ${ }^{2}$ Cadre' s sanitarium, 62101 Army of PLA, 67 Nahu Road, Xinyang 464000, Henan, China. ${ }^{3}$ Department of General Surgery, No. 534 Hospital of PLA, Yingzhou Road, Luoyang 471000, Henan, China. ${ }^{4}$ Department of General Surgery, No. 91 Hospital of PLA, 239Gongye Road, Jiaozuo 454000, Henan, China.

Received: 5 December 2017 Accepted: 28 August 2018 Published online: 03 September 2018

\section{References}

1. Fock KM. Review article: the epidemiology and prevention of gastric cancer. Aliment Pharmacol Ther. 2014;40(3):250-60. 
2. Chen W, Zheng R, Baade PD, Zhang S, Zeng H, Bray F, et al. Cancer statistics in China, 2015. CA Cancer J Clin. 2016;66(2):115-32.

3. Sitarz R, Skierucha M, Mielko J, Offerhaus GJA, Maciejewski R, Polkowski WP. Gastric cancer: epidemiology, prevention, classification, and treatment. Cancer Manag Res. 2018;10:239-48.

4. Giampieri R, Del Prete M, Cantini L, Baleani MG, Bittoni A, Maccaroni E, et al. Optimal management of resected gastric cancer. Cancer Manag Res. 2018; 10:1605-18.

5. Goetze OT, Al-Batran SE, Chevallay M, Mönig SP. Multimodal treatment in locally advanced gastric cancer. Updat Surg. 2018;70(2):173-9.

6. Marano L, Polom K, Patriti A, Roviello G, Falco G, Stracqualursi A, et al. Surgical management of advanced gastric cancer: an evolving issue. Eur $J$ Surg Oncol. 2016;42(1):18-27.

7. Zhang J, Gan L, Xu MD, Huang M, Zhang X, Gong Y, et al. The prognostic value of age in non-metastatic gastric cancer after gastrectomy: a retrospective study in the U.S. and China. J Cancer. 2018;9(7):1188-99.

8. Deng J, Zhang R, Pan Y, Ding X, Cai M, Liu Y, et al. Tumor size as a recommendable variable for accuracy of the prognostic prediction of gastric cancer: a retrospective analysis of 1,521 patients. Ann Surg Oncol. 2015;22(2):565-72.

9. Japanese Gastric Cancer Association. Japanese classification of gastric carcinoma: 3rd English edition. Gastric Cancer. 2011;14(2):101-12.

10. Kunisaki C, Akiyama H, Nomura M, Matsuda G, Otsuka Y, Ono HA, et al. Clinicopathologic characteristics and surgical outcomes of mucinous gastric carcinoma. Ann Surg Oncol. 2006;13(6):836-42.

11. Hsu JT, Wang CW, Le PH, Wu RC, Chen TH, Chiang KC, et al. Clinicopathological characteristics and outcomes in stage I-III mucinous gastric adenocarcinoma: a retrospective study at a single medical center. World J Surg Oncol. 2016;14:123.

12. Wang Z, Zhang X, Hu J, Zeng W, Zhou Z. Clinicopathological features and outcomes in patients undergoing radical resection for early gastric cancer with signet ring cell histology. J Visc Surg. 2015;152(6):357-61.

13. Postlewait LM, Squires MR, Kooby DA, Poultsides GA, Weber SM, Bloomston $\mathrm{M}$, et al. The prognostic value of signet-ring cell histology in resected gastric adenocarcinoma. Ann Surg Oncol. 2015;22(Suppl 3):S832-9.

14. Piessen G, Messager M, Leteurtre E, Jean-Pierre T, Mariette C. Signet ring cell histology is an independent predictor of poor prognosis in gastric adenocarcinoma regardless of tumoral clinical presentation. Ann Surg. 2009; 250(6):878-87.

15. Cai L, Li Y, Sun L, Guo M, Lian X, Xiao S, et al. Clinicopathological characteristics and prognosis in patients with mucinous gastric carcinoma after D2 radical gastrectomy. Int J Clin Exp Pathol. 2017;2(10):2024-9.

16. Japanese Gastric Cancer Association. Japanese gastric cancer treatment guidelines 2010 (ver. 3). Gastric Cancer. 2011;14(2):113-23.

17. Bamboat ZM, Tang LH, Vinuela E, Kuk D, Gonen M, Shah MA, et al. Stagestratified prognosis of signet ring cell histology in patients undergoing curative resection for gastric adenocarcinoma. Ann Surg Oncol. 2014;21(5): $1678-85$.

18. Shim JH, Song KY, Kim HH, Han SU, Kim MC, Hyung WJ, et al. Signet ring cell histology is not an independent predictor of poor prognosis after curative resection for gastric cancer: a propensity analysis by the KLASS group. Medicine (Baltimore). 2014;93(27):e136.

19. Lu M, Yang Z, Feng Q, Yu M, Zhang Y, Mao C, et al. A retrospective cohort study of 2199 consecutive patients. Medicine (Baltimore). 2016;95(27):e4052.

20. Yin C, Li D, Sun Z, Zhang T, Xu Y, Wang Z, et al. Clinicopathologic features and prognosis analysis of mucinous gastric carcinoma. Med Oncol. 2012; 29(2):864-70.

21. Tanaka K, Shimura T, Kitajima T, Kondo S, Ide S, Okugawa Y, et al. Tropomyosin-related receptor kinase B at the invasive front and tumour cell dedifferentiation in gastric cancer. Br J Cancer. 2014;1 10(12):2923-34.

22. Wang P, Wan WW, Xiong SL, Feng H, Wu N. Cancer stem-like cells can be induced through dedifferentiation under hypoxic conditions in glioma, hepatoma and lung cancer. Cell Death Discov. 2017;3:16105.

23. Cui T, Srivastava AK, Han C, Wu D, Wani N, Liu L, et al. DDB2 represses ovarian cancer cell dedifferentiation by suppressing ALDH1A1. Cell Death Dis. 2018;9(5):561

24. Xie VK, Li Z, Yan Y, Jia Z, Zuo X, Ju Z, et al. DNA-methyltransferase 1 induces dedifferentiation of pancreatic Cancer cells through silencing of Krüppel-like factor 4 expression. Clin Cancer Res. 2017;23(18):5585-97.

25. Axelson H, Fredlund E, Ovenberger M, Landberg G, Påhlman S. Hypoxiainduced dedifferentiation of tumor cells--a mechanism behind heterogeneity and aggressiveness of solid tumors. Semin Cell Dev Biol. 2005;16(4-5):554-63

26. Friedmann-Morvinski D, Verma IM. Dedifferentiation and reprogramming: origins of cancer stem cells. EMBO Rep. 2014;15(3):244-53.

27. Lee $\mathrm{HH}$, Song $\mathrm{KY}$, Park $\mathrm{CH}$, Jeon $\mathrm{HM}$. Undifferentiated-type gastric adenocarcinoma: prognostic impact of three histological types. World $J$ Surg Oncol. 2012;10:254
Ready to submit your research? Choose BMC and benefit from:

- fast, convenient online submission

- thorough peer review by experienced researchers in your field

- rapid publication on acceptance

- support for research data, including large and complex data types

- gold Open Access which fosters wider collaboration and increased citations

- maximum visibility for your research: over $100 \mathrm{M}$ website views per year

At BMC, research is always in progress.

Learn more biomedcentral.com/submissions 